\title{
Aspectos sanitários do úbere e composição química do leite de cabras Saanen
}

\author{
The health's udder and chemical composition of Saanen goat milk \\ Marcele Vilanova ${ }^{1}$, Michelle Gonçalves ${ }^{2}$, Maria Teresa Moreira Osório ${ }^{2}$, Roger Esteves ${ }^{2} \&$ Verônica \\ Schmidt ${ }^{3}$
}

\begin{abstract}
RESUMO
$\mathrm{O}$ incremento na cadeia produtiva caprina tem-se intensificado nos últimos anos. Entretanto, pouco se conhece sobre as características qualitativas do leite dessa espécie. Neste sentido, objetivaram-se caracterizar a composição química do leite de cabras Saanen em sistema semi-intensivo de produção, durante as fases de pico e decréscimo da produção leiteira. Determinou-se, ainda, a relação entre "Califórnia Mastitis Test" (CMT) e Contagem de Células Somáticas (CCS), como avaliadores da sanidade do úbere nessa espécie. Quinze animais foram acompanhados durante quatro meses, recebendo alimentação de acordo com a rotina da propriedade, sem controle quanti ou qualitativo. Para as análises de composição química e sanidade, coletaram-se 238 amostras na ordenha da manhã, em intervalos semanais, dos meses de dezembro a março. Os teores percentuais médios de gordura, proteína bruta, lactose e sólidos totais, no período, foram 2,76 $\pm 0,70 ; 2,67 \pm 0,25$; $3,97 \pm 0,20$ e 10,13 $\pm 0,86$, respectivamente. Estes valores indicam uma tendência de deficiência no atendimento às necessidades nutricionais das fêmeas em lactação e o possível comprometimento da matéria prima à produção de derivados lácteos. Não se observou alteração clínica no sistema mamário dos animais, tampouco isolamento bacteriano do leite. No entanto, verificou-

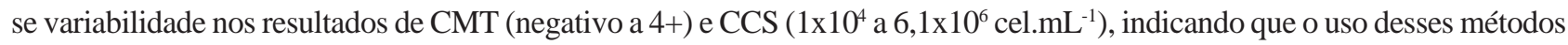
requer cautela no diagnóstico de mastite em cabras Saanen, uma vez que, nessa espécie, o aumento celular pode ser causado por outros fatores além da infecção da glândula mamária.
\end{abstract}

Descritores: leite caprino, Saanen, CCS, CMT.

\section{ABSTRACT}

The increase in the milk goat's production chain has been intensified in recent years. However, little is known about the quality characteristics of goat's milk. In this sense, the objective of this paper is to characterize the composition of Saanen goat milk in semi-intensive production system, during the stages of peak and decline in milk production. It was determined the relationship between the California Mastitis Test (CMT) and Somatic Cell Count (SCC), as evaluators of the health udder in this species. Fifteen animals were attended for four months, in accordance with the farm routine, without control of nutritional level. Were collected 238 samples of milk in the milking, in weekly intervals from December to March. The average percentage of fat content, crude protein, lactose and solids total in the period were $2.76 \pm 0.70 ; 2.67 \pm 0.25 ; 3.97 \pm 0.20$ and $10.13 \pm 0.86$, respectively. These figures indicate a trend of disability in attendance to nutritional needs of females and the possible compromising of the raw material for the production of dairy. There was no clinical mastitis, nor bacterial isolation in milk. However, there was variability in the results of CMT (negative to $4+)$ and CCS $\left(6.1 \times 10^{6}\right.$ the $\left.1 \times 10^{4} \mathrm{cel}_{\mathrm{mL}} \mathrm{mL}^{-1}\right)$, indicating that the use of these methods requires caution in the diagnosis of mastitis in Saanen goats, once that this kind increase the cell can be caused by other factors besides the infection of the mammary gland.

Key words: goat's milk, Saanen goat, SCC, CMT. CORRESPONDÊNCIA: V. Schmidt [veronica.schmidt@ufrgs.br; Fone: +(55) 5133088030 / Fax: +(55) 513308 7305]. 


\section{INTRODUÇÃO}

A produção de leite caprino no Estado é uma fonte viável de renda ao produtor rural, especialmente em sistemas de agricultura familiar. Vários fatores têm contribuído para o desenvolvimento da atividade, no entanto, são poucos os dados sobre composição físico-química e sanidade nessa espécie.

Conhecer a composição do leite é essencial para determinar sua qualidade, a qual define propriedades organolépticas e industriais. Os parâmetros de qualidade são cada vez mais utilizados para detecção de falhas nas práticas de manejo, servindo como referência na valorização da matéria-prima [7]. Os principais parâmetros utilizados em programas de qualidade industrial do leite são os conteúdos de gordura, proteína, sólidos totais e CCS [16]; sendo esta uma ferramenta valiosa na avaliação da sanidade do úbere, estimativa de perdas quanti e qualitativas de produção de leite e derivados, no indicativo da qualidade do leite produzido na propriedade e para estabelecer medidas de prevenção e controle da mastite [18].

A mastite subclínica, um dos maiores problemas da caprinocultura leiteira, resulta em perdas de produtividade e não possui métodos diagnósticos padronizados para a espécie.

O CMT, juntamente com a CCS, é um ótimo indicador da mastite subclínica em bovinos. No entanto, a utilização dessa metodologia em caprinos ainda é controversa [31], uma vez que, a composição do leite, nessa espécie, apresenta grande variabilidade em função de influências genéticas, alimentares e ambientais, além daquelas inerentes ao próprio animal [2]. Desse modo, este trabalho tem por objetivos descrever a composição química do leite e estimar a relação existente entre CMT e CCS, na avaliação da sanidade do úbere em cabras Saanen.

\section{MATERIAIS E MÉTODOS}

No presente trabalho, utilizou-se amostragem por conveniência [34], realizando-se visitas semanais no período de dezembro de 2005 a março de 2006, a um criatório de caprinos da raça Saanen localizado no município de Capão do Leão, RS. A propriedade utiliza sistema de criação semi-intensivo, não realizando o controle qualitativo nem quantitativo do alimento fornecido, sendo a base da alimentação pastagem de azevém e aveia e suplementação concentrada no cocho, composta por farelo de arroz, farelo de soja, milho moído e sal mineral caprino. Os quinze animais, ordenhados manualmente, encontravam-se entre o período de platô e de decréscimo da produção leiteira [9], com quatro meses ou mais de lactação.

Antes e após a ordenha matinal, foi realizado exame clínico da glândula mamária de todas as fêmeas do estudo. O CMT foi realizado logo em seguida ao exame clínico, usando um tenso-ativo aniônico como reagente [30], e as reações foram interpretadas como anteriormente descrito [14]. Coletaram-se assepticamente 238 amostras de leite individualizadas por teto, as quais foram transportadas sob refrigeração e analisadas, em intervalo inferior a seis horas, para presença de mastite subclínica [30].

Os animais foram ordenhados manualmente e, o leite ejetado, coletado em jarras, individualizado por teto. Após realizado o esgotamento do úbere, o conteúdo de cada glândula mamária foi homogeneizado por turbilhonamento e separada uma alíquota de 50 $\mathrm{mL}$ em frasco plástico, os quais foram encaminhados ao Laboratório de Análise de Leite da Embrapa Clima Temperado, para a determinação dos teores percentuais de gordura, proteína bruta, lactose e sólidos totais através de espectrofotometria por radiação infravermelho [3] e a contagem eletrônica de células somáticas foi efetuada no equipamento Somacount 300, calibrado com leite de vaca, de acordo com recomendações da International Dairy Federation [12].

$\mathrm{Na}$ análise estatística, utilizaram-se os programas GraphPad Prism 4.0 aplicando um nível de significância de 5\%. Os dados de CMT e os parâmetros químicos foram analisados considerando cada glândula, uma unidade amostral [17]. A associação entre o CMT e a CCS [27] foi calculada pelo teste de McNemar e índice Kappa e, a correlação, pelo teste de Spermann. As variações mensais dos parâmetros avaliados foram determinadas pelo teste de Kruskal-Wallis e Teste de Dunn, para comparações múltiplas.

\section{RESULTADOS}

Não se evidenciaram fêmeas com sintomatologia clínica compatível com mastite clínica. Da mesma forma, não foi observado crescimento bacteriano no leite coletado. Na maioria $(78,95 \%)$ das metades mamárias avaliadas não se observou resposta ao CMT e, em 20 (21,05\%), observou-se reação 2, 3 ou 4. Determinaram-se contagens de células somáticas de $1 \times 10^{4}$ a $6,1 \times 10^{6}$ cel. $\mathrm{mL}^{-1}$. No mês de dezembro, 
observou-se CCS significativamente menor do que em janeiro e fevereiro; verificando-se uma tendência na redução desse valor de janeiro a março. Constatou-se diferença significativa nas CCS das amostras de leite que apresentaram reação positiva $(\geq 1+)$ frente

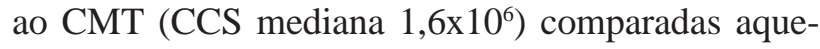
las com CMT negativo (CCS mediana 2,9x105) $(\mathrm{p}<0,001)$ e suspeito (CCS mediana $\left.6,1 \times 10^{5}\right)(p<0,05)$. Considerando-se $2 \times 10^{6}$ cel.mL ${ }^{-1}$ [27] como limite fisiológico do leite caprino, determinou-se associação significativa $(\mathrm{p}=0,0001)$ entre os resultados do CMT e a CCS, porém, moderada $(\mathrm{k}=0,430)$. Verificou-se, ainda, correlação fraca $(r=0,4498)$, porém significativa ( $p<0,0001$ ) entre os resultados do CMT e a CCS nas metades mamárias.

Observaram-se variações na composição química no decorrer dos meses de coleta, onde os atributos que mostraram tendência ao aumento foram a gordura e os sólidos totais, os quais apresentaram diferença significativa $(p<0,05)$ apenas entre os meses de dezembro e março ( $26 \%$ e $6 \%$, respectivamente). A proteína bruta comportou-se de maneira semelhante, porém, apresentou uma ligeira queda entre os meses de dezembro e janeiro (150 a 180 dias de lactação), voltando a aumentar em seguida. Entretanto, verificou-se diferença significativa $(p<0,05)$ apenas entre os meses de dezembro e março (10\%). O único atributo que se comportou de maneira oposta foi a lactose, que apresentou uma queda de $4,11 \%$ significativa ( $\mathrm{p}<0,05)$, no mesmo período.

Na Tabela 1 são apresentados os percentuais médios mensais dos atributos estudados e a média do período de avaliação.

\section{DISCUSSÃO}

A mastite é a inflamação da glândula mamária que pode ser causada por mais de 140 diferentes microorganismos. Pode apresentar-se sem sinais clínicos (forma subclínica) ou com anormalidades visíveis (forma clínica aguda ou subaguda), onde serão evidenciados úbere avermelhado, calor local, sensibilidade ao toque e, em alguns casos, endurecido quando palpado [21]. No presente estudo, tanto no exame clínico quanto no bacteriológico, não se evidenciou animais positivos para mastite. Diferentemente, em estudo realizado na Região do Vale do Taquari/RS, 30,8\% das metades mamárias avaliadas apresentaramse positivas para mastite subclínica no exame microbiológico [19].

Considerando que a espécie caprina apresenta uma grande quantidade de células epiteliais e partículas anucleadas [33], esperava-se um número maior de respostas positivas ao CMT, ao contrário do observado $(21,05 \%)$, uma vez que o escore elevado nesse teste é normal para caprinos [11].

Os valores para CCS encontrados neste trabalho reforçam a grande variação desse parâmetro na espécie caprina, uma vez que, em diferentes estágios fisiológicos, valores entre 844.000 e 1.440 .000 $\mathrm{cel} / \mathrm{mL}$ tem sido relatados com freqüência [5]. Entretanto, a indicação da CCS no diagnóstico da mastite subclínica tem variado de $500 \times 10^{3}$ cel./mL [4] à $1.000 \times 10^{3} \mathrm{cel} . / \mathrm{mL}[20]$.

Por possuir um custo relativamente baixo e rapidez na obtenção de resultados, a CCS vem sendo utilizada para o monitoramento da sanidade dos rebanhos

Tabela 1. Composição percentual média mensal e no período de avaliação, do leite de cabras Saanen.

\begin{tabular}{cccccc}
\hline $\begin{array}{c}\text { Atributos } \\
(\%)\end{array}$ & dezembro & janeiro & fevereiro & março & Período \\
\hline Gordura & $2,36^{\mathrm{a}}$ & $2,90^{\mathrm{ab}}$ & $2,79^{\mathrm{ab}}$ & $2,98^{\mathrm{b}}$ & 2,76 \\
Proteína bruta & $2,60^{\mathrm{a}}$ & $2,54^{\mathrm{a}}$ & $2,62^{\mathrm{a}}$ & $2,87^{\mathrm{b}}$ & 2,67 \\
Lactose & $4,11^{\mathrm{a}}$ & $3,87^{\mathrm{b}}$ & $3,95^{\mathrm{b}}$ & $3,95^{\mathrm{b}}$ & 3,97 \\
Sólidos Totais & $9,99^{\mathrm{a}}$ & $10,14^{\mathrm{ab}}$ & $10,24^{\mathrm{ab}}$ & $10,67^{\mathrm{b}}$ & 10,26 \\
CCS & $232.500^{\mathrm{a}}$ & $1.059 .000^{\mathrm{b}}$ & $788.500^{\mathrm{b}}$ & $500.000^{\mathrm{ab}}$ & 645.000 \\
\hline
\end{tabular}

* Letras diferentes na mesma linha indicam diferença estatística significativa $(p<0,05)$. 
leiteiros em todo o mundo, tornando-se uma ferramenta de gerenciamento para determinar a prevalência de infecções intramamarias [15]. Entretanto, na espécie caprina, além da infecção intramamária, a CCS pode sofrer variações segundo idade [6, 29], fase de lactação $[6,13,26]$, nível de produção de leite [39] e infecção pelo vírus da artrite encefalite caprina [28], podendo ser um ou vários desses fatores os responsáveis pelas alterações ocorridas durante os quatro meses de análise do presente estudo.

A associação entre CMT e CCS, considerando valores de CCS > 2.000 .000 cel. $\mathrm{mL}^{-1}$ como indicativo de infecção da glândula mamária, foi anteriormente observada [36], semelhante aos resultados encontrados no presente estudo. Sendo que CMT $\geq 2$ apresenta o melhor conjunto de sensibilidade $(70,50 \%)$ e especificidade $(75 \%)$ como método de triagem da mamite caprina [31].

Pesquisas indicam que os valores de proteína bruta, gordura e lactose aumentam no decorrer da lactação [1], diferindo do observado, no qual apenas os atributos gordura e sólidos totais aumentaram significativamente. Essa diferença pode ser devida a fatores como condições do clima, período de lactação e disponibilidade de alimentos, os quais podem afetar a composição, as características físico-químicas e a produção de leite [1].

A composição básica do leite caprino é descrita com 3,8\% de gordura, 4,08\% de lactose, 2,90\% de proteína bruta [23]. Entretanto, oscilações no teor de gordura podem ser provocadas por fatores como turno de ordenha e raça. Algumas raças se caracterizam pela baixa produção de leite com alto teor de gordura, como a raça Anglo-Nubiana, ou pela elevada quantidade de leite com baixo teor de gordura, como a raça Saanen [22]. O genótipo puro do rebanho estudado poderia explicar os baixos percentuais de gordura observados.

Por outro lado, animais da mesma raça, no Rio Grande do Sul, apresentaram valores superiores ao observado (gordura: 3,25\%; proteína bruta: 3,42\%; lactose: $4,30 \%$ e sólidos totais: $11,91 \%$ ) [38], sugerindo um suprimento insuficiente às exigências das fêmeas acompanhadas, resultando em diminuição dos teores da maioria dos atributos, efeitos já relatados por [32] para proteína bruta.

Os teores de proteína bruta tendem a diminuir até aproximadamente 120 dias de lactação [8], aproximando-se do encontrado neste estudo. Neste sentido, alguns autores [5] afirmaram que a tendência dos teores de proteína e gordura segue uma evolução inversa à da produção de leite, alcançando valores mínimos no segundo mês de lactação, que coincidem com a produção máxima de leite. Os dados da literatura são controversos quanto ao percentual de proteína em relação ao período de lactação. Alguns autores afirmam que o conteúdo de proteína decresce no decorrer da lactação [8, 37], enquanto outros afirmam o contrário [35].

O teor de lactose é influenciado pelos diferentes níveis de concentrado da dieta, apresentando diferenças ao longo da lactação [10]. No presente estudo não ocorreu controle da produção leiteira; entretanto, a diminuição nos teores de lactose sugere uma menor produção de leite. Sendo um dos nutrientes mais estáveis na composição química do leite, ela está diretamente relacionada à regulação da pressão osmótica, de modo que, maior produção de lactose, determina maior produção de leite [22].

\section{CONCLUSÕES}

A composição química do leite de cabras Saanen, criadas em sistema semi-intensivo sem controle nutricional, tende a ser inferior a dos criatórios que dedicam atenção especial às exigências das fêmeas em lactação, sendo a nutrição um dos pontos críticos na criação racional de cabras leiteiras.

$\mathrm{Na}$ avaliação da sanidade do úbere de fêmeas caprinas, os testes de CMT e CCS necessitam cautela para uma interpretação correta do resultado.

\section{REFERÊNCIAS}

1 Aganga A.A., Amarteifio J.O. \& Nkile N. 2002. Effect of stage of lactation on nutrient composition of Tswana sheep and goat's milk. Journal of Composition and Analysis. 15: 533-543.

2 Aguirre S.I.A. 1986. Producción de caprinos. México: AGF, 695p.

3 Bentley Instruments. 1995. Bentley 2000: Operator's Manual. Chaska: Bentley. 77p.

4 Contreras A., Sierra D., Corrales J.C., Sanchez A. \& Marco J. 1996. Physiological threshold of somatic cell count and California Mastitis Test for diagnosis of caprine subclinical mastitis. Small Ruminant Research. 21: 259-264. 
5 Corrales J.C., Contreras A., Sánchez A., Marco J. \& Sierra D. 1994. Contajes de células somáticas en leche de cabras murciano-granadinas al final del periodo de lactación y su realación con la edad y la presencia de infección intramamaria. Producción ovina y caprina: XVIII Jornadas de la Sociedad Española de Ovinotecnia y Caprinotecnia. Albacete/Espanha, pp. 201-207.

6 Dulin A.M., Paape M.J., Schultze W.D. \& Weinland B.T. 1983. Effect of parity, stage of lactation and intramammary infection on concentrations of somatic cells and cytoplasmic particles in goat milk. Journal of Dairy Science. 66: $2426-2433$.

7 Dürr J.W. 2004. Programa nacional de melhoria da qualidade do leite: uma oportunidade única. In: Dürr J.W., Carvalho M.P. \& Santos M.V. (Eds.). O compromisso com a qualidade do leite no Brasil. Passo Fundo: UPF. pp. 38-55.

8 Faria V.M.C.O. 1987. Estudo do rendimento e composição do leite de cabra na região Nordeste: raça Saanen. Campinas: Universidade Estadual de Campinas, 1987. 95p. Dissertação (Mestrado em Tecnologia de Alimentos) - Universidade Estadual de Campinas, 1987.

9 Garcia A.A. 1981. Caprinotecnia. México: Guadalajara. 840p.

10 Goetsch A.L., Detweiler G. \& Salhu T. 2001. Dairy goat performance with different dietary concentrate levels in late lactation. Small Ruminant Research. 41: 117-125.

11 Gus S.B. \& Ace D.L. 1992. Mastitis. In: Goat Handbook. USA: National Agricultural Library. Disponível em: <http:// www.inform.umd.edu/EdRes/Topic/AgrEnv/ndd/goat>. Acessado em 08/2001.

12 International Dairy Federation. 1995. Milk: Enumeration of somatic cell. Brussels: IDF/FIL (IDF Standard 148 A). 8p.

13 Kalogridou-Vassilliadou D., Manolkidis K. \& Tsigoida A. 1992. Somatic cell counts in relation to infection status of the goat udder. Journal of Dairy Research. 59: 21-28.

14 Lima Junior A.D., Pessoa A.L.P., Sa D.A. \& Oliverira A.A.F 1994. Fatores condicionantes da mamite caprina em Pernambuco. In: Congresso Brasileiro de Medicina Veterinária (Olinda/Pe). pp. 157

15 McDougall S. \& Voermans M. 2002. Influence of Estrus on Somatic Cell Count in Dairy Goats. Journal of Dairy Science. 85: $378-383$.

16 Monardes H. 1998. Programa de pagamento de leite por qualidade Quebec, Canadá. In: I Simpósio Internacional sobre Qualidade do Leite (Curitiba, PR). pp. 40-43.

17 Moroni P., Pisoni, G., Antonini M., Rufo G., Varisco G. \& Boettcher P. 2005. Subclinical mastitis and antimicrobial suscetibility of Staphylococcus caprae and Staphylococcus epidermidis isolated from two Italian goat herds. Journal of Dairy Science. 88: 1694-1704.

18 Müller E.E. 2002. Qualidade do leite, células somáticas e prevenção da mastite. In: II Simpósio sobre Sustentabilidade da Pecuária Leiteira na Região Sul do Brasil. (Maringá, PR) pp. 206-217.

19 Muricy R.F. 2003. Ocorrência de mamite subclínica em caprinos e qualidade higiênico-sanitária do leite produzidos em propriedades associadas à cooperativa Languiru, Teutônia - RS. 83p. Dissertação (Mestrado em Ciências veterinárias) Programa de Pós-Graduação em Ciências Veterinárias, Faculdade de Veterinária, Universidade Federal do Rio Grande do Sul, Porto Alegre.

20 Perrin G.G., Mallereau M. P., Lenfant D. \& Baudry C. 1997. Relationships between California mastitis test (CMT) and somatic cell counts in dairy goats. Small Ruminant Research. 26: 167.

21 Philpot W.N. \& Nickerson S.C. 2002. Vencendo a luta contra a mastite. São Paulo: Westfalia Landtechnik do Brasil Ltda., $188 \mathrm{p}$.

22 Queiroga R.C.R.E., Costa R.G., Biscontini T.M.B., Medeiros A.N., Madruga M.S. \& Schuler A.R.P. 2007. Influência do manejo do rebanho, das condições higiênicas da ordenha e da fase de lactação na composição química do leite de cabras Saanen. Revista Brasileira de Zootecnia. 36: 430-437.

23 Ribeiro S.D.A. 1998. Caprinocultura: criação racional de caprinos. São Paulo: Nobel, 318p.

25 Rota A.M., Rodriguez P., Rojas A., Martin L. \& Tovar J. 1993. Quantitative changes in the milk of Veratá goats during lactation. Archivos Zootecnia. 42: 137-146.

26 Rota A.M., Gonzalo C., Rodriguez P.L., Rojas A.I., Martin L. \& Tovar J.J. 1993. Somatic cell types in goats milk in relation to total cell count, stage and number of lactation. Small Ruminant Research. 12: 89-98.

27 Rota A. M., Rojas A., Martin L., Rodriguez, P. \& Tovar J.J. 1994. Uso de la prueba de California para detección de mamitis en el ganado caprino. Avances en Alimentacion y Mejora Animal. 2: 67-69.

28 Ryan D.P., Greenwood P.L. \& Nicholls P.J. 1993. Effect of caprine arthritis-encephalitis virus-infection on milk cell count and n-acetyl-beta-glucosaminidase activity in dairy goats. Journal of Dairy Research. 60: 299-306. 
29 Sanchez A., Contreras A. \& Corrales J.C. 1999. Parity as a risk factor for caprine subclinical intramammary infection. Small Ruminant Research. 31: 197-201.

30 Santos A.R., Scherer S. \& Schmidt V. 2004. Contagem de células somáticas e "California Mastitis Test" como método diagnóstico da mamite em caprinos. Revista de Ciências Agroveterinárias. 3: 50-55.

31 Santos L.F., Castro R.S. \& Costa E.O. 1995. "California Mastitis Test" e "Whiteside modificado" como critério de triagem para mastite caprina. Pesquisa Agropecuária Brasileira. 30: 295-298.

32 Sanz Sampelayo M.R.S., Pérez L., Alonso M.J.J., Amigo L. \& Boza J. 2002. Effects of concentrates with different contents of protected fat rich PUFAs on the performance lactating Granadina goats. Part II. Milk production and composition. Small Ruminant Research. 43: 141-148.

33 Silva E.R., Saukas T.N., Alves F.S.F. \& Pinheiro R.R. 1996. Contagem de células somáticas e "California Mastitis Test" no diagnóstico da mamite caprina subclínica. Revista Brasileira de Medicina Veterinária. 18: 78-83.

34 Thrusfield M. 2004. Epidemiologia Veterinária. São Paulo: ROCA. 556p.

35 Veinoglou D., Baltadjieva M. \& Kalatzotoulos G. 1982. La composition de lait de chevre de la région de Plovidven Bulgarie et la Loannina en Gréce. Le Lait. 62: 155-165.

36 Vilanova M.S., Schmidt V., Pradiée J., Gonçalves M., Ladeira S. L., Esteves R.M.G., Cardoso F.M., Martins L.R., Sphor L. \& Osório M.T.M. 2007. Sanidade do úbere de cabras saanen no Rio Grande do Sul: contagem de células somáticas e “California Mastitis Test”. In: VI Congresso Internacional do Leite. (Resende/RJ). 1 CD-ROM.

37 Voutsinas L., Pappas C. \& Katsiari M. 1990. The composition of Alpine goats milk during lactation in Greece. Journal of Dairy Research. 57: 45-51.

38 Zanela M.B., Schmidt V., Pinto A.T., Machado M., Souza A.C.S., Silva F.F.P. \& Ribeiro M.E.R. 2006. Produção e composição química do leite de cabra na Expointer 2006 - RS. In: II Congresso Brasileiro da Qualidade do Leite (Goiânia). 1 CD-ROM.

39 Zeng S.S. \& Escobar E.N. 1995. Effect of parity and milk production on somatic cell count, standard plate count and composition of goat milk. Small Ruminant Research. 17: 269-274. 